\title{
Development of New Isolation and Quantification Method of Piperine from White Pepper Seeds (Piper Nigrum L) Using A Validated HPLC
}

\author{
Nindya Kusumorini ${ }^{1}$, Akhmad Kharis Nugroho ${ }^{2 *}$, Suwijiyo Pramono ${ }^{3}$ and Ronny Martien ${ }^{2}$
}

1. Doctoral Program in Pharmaceutical Science, Faculty of Pharmacy, Universitas Gadjah Mada, Yogyakarta 55281 Indonesia

2. Department of Pharmaceutics, Faculty of Pharmacy, Universitas Gadjah Mada, Yogyakarta 55281 Indonesia

3. Department of Pharmaceutical Biology, Faculty of Pharmacy, Universitas Gadjah Mada, Yogyakarta 55281 Indonesia

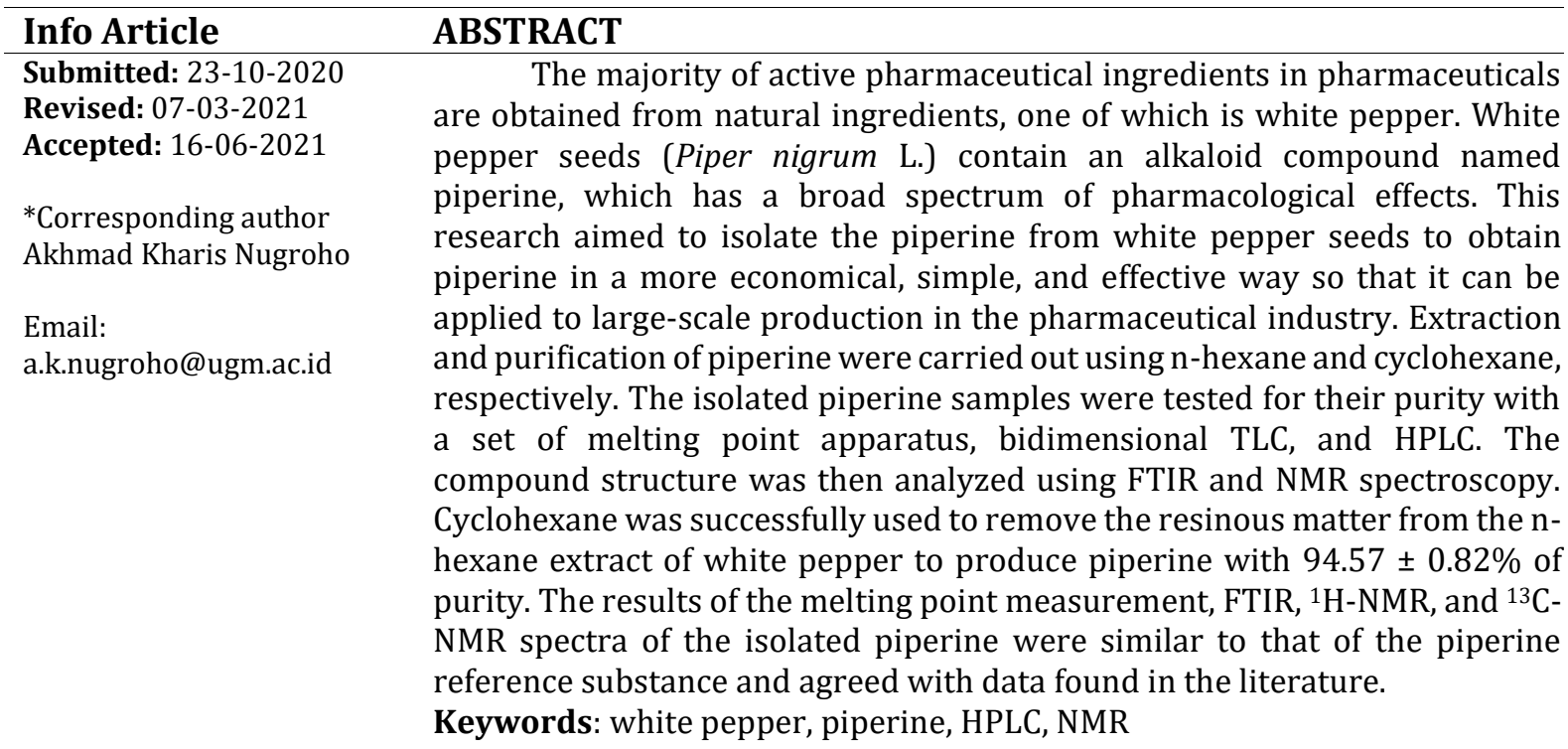

\section{INTRODUCTION}

Indonesia is a tropical country with rich plant diversity. There are around 30,000 plants in Indonesia, and approximately 3,000 of those have been reported to have medicinal benefits. Still, only a few Indonesian plants have been used in the industry of traditional medicines. One of such plants is white pepper ( $P$ nigrum). It contains essential oils (1-2.5\%) and alkaloids (5-9\%), of which the major constituents are piperine (1.7$7.4 \%$ ), chavicine, and piperidine. (Khan et al., 2010) Piperine has many pharmacological benefits, including for the treatment of pain during menstruation, tuberculosis, sleep disorders, respiratory infections, and arthritis, as well as anticonvulsant, antiulcer, anti-inflammatory, antibacterial, antioxidant, anticancer, antidepressant, and antiplatelet aggregation (Ee et al., 2010; Han et al., 2008; Koul and Kapil, 1993; Li et al., 2007; Mujumdar et al., 1990; Srinivasan,
2007). For example, piperine can be used to treat osteoarthritis by restraining the activity of enzymes responsible for the synthesis of leukotriene and prostaglandin, NO (Nitric Oxide), and TNF- $\alpha$ (tumor necrosis factor- $\alpha$ ) (Umar et al., 2013). Several studies have also reported that piperine significantly inhibits the activation of NF- $\kappa$ B induced by IL- $1 \beta$, as well as inhibiting COX2, PGE2, iNOS, NO, and MMPs that play a role in osteoarthritis ( Li et al., 2017; Ying et al., 2013).

Currently, efforts to isolate piperine compounds have been widely reported. However, methods to obtain pure compounds require complicated, ineffective steps, and lack economic value, especially when produced on a large scale. So far, the most widely used method of isolating piperine compounds is by using ethanol, followed by washing using potassium hydroxide to remove resinous matter (Chaudhri, 2017; Rahman et al., 2011; Saha et al., 2014). However, the use of 
potassium hydroxide can catalyze the hydrolysis of piperine to piperidine and piperic acid (Ikan, 2013). Therefore, further studies into the more appropriate method for isolating piperine on a large scale are still needed.

This study aimed to isolate piperine from white pepper seeds in a simple, economical, and effective manner by avoiding the alteration of the active substance. In this study, isolation of piperine was carried out using the Soxhlet method to minimize the amount of solvents used for the extraction. The solvent selection approach was based on piperine's non-polarity, which was easier to extract using non-polar solvents.

\section{MATERIALS AND METHODS Instrumentation}

The instruments used in the research include a set of Soxhlet extractors, melting point apparatus (Stuart Scientific, UK), UV254 lamp, FTIR spectrophotometer (Thermo Scientific Nicolet iS10), HPLC Hitachi L-2420 UV-Vis detector with Luna ${ }^{\circledR} 5 \mu \mathrm{M}$ C18 $100 \AA$ LC Column 250 x 4.6mm Phenomenex, and NMR spectrophotometer (JNM-ECZ500R, 500MHz Super Conductive Magnets).

\section{Materials}

White pepper was collected from farmers in Sorowako, South Sulawesi. Piperine reference compound was obtained from E.Merck, China, with a purity of $\geq 98 \%$. Silica gel 60 F254 plates for thinlayer chromatography (TLC) were obtained from E.Merck, Germany. All pro analysis solvents such as methanol, ethanol, n-hexane, cyclohexane, ethyl acetate, acetic acid were obtained from E.Merck.

\section{Extraction and purification of piperine}

White pepper powder was extracted using Soxhlet apparatus and n-hexane in the first method and ethanol in the second one. The extract was tested on a silica gel TLC plate with n-hexane ethyl acetate $(7: 3)$ as a mobile phase to choose the best extraction method by comparing TLC profiles of the extracts to that of the piperine reference substance. The selected menstruum was evaporated until only half of the volume left and then stored in the refrigerator to form crystals, which were then referred to as the semipurified white pepper fraction. After the filtration process, the obtained crystals were washed by cyclohexane. The insoluble cyclohexane fraction was dried at $25^{\circ} \mathrm{C}$ and tested by TLC, HPLC, and melting point measurement. The compound structure was analyzed using FTIR and NMR spectroscopy.

\section{Melting point}

The melting point of isolated piperine was measured using a set of melting point apparatus. A melting point test was carried out on isolated piperine and piperine reference substances to compare the obtained results.

\section{Bidimensional Thin-Layer Chromatography}

The isolated piperine in the methanolic solution was spotted on TLC silica gel 60 F254 plates. It was first eluted with n-hexane - ethyl acetate (9:5) and then with cyclohexane chloroform (1:4). The chromatogram was visualized under UV 254 and $366 \mathrm{~nm}$.

\section{FTIR spectroscopy}

FTIR spectroscopy test was carried out to determine types of chemical bonds of sample constituents in the range of wavelengths of 400$4000 \mathrm{~cm}^{-1}$. FTIR testing was performed using an Mb3000 FTIR spectrophotometer combined with the intuitive Horizon MBTM FTIR software. The samples, isolated piperine, and piperine reference substances were prepared beforehand in a $1 \% \mathrm{KBr}$ powder mixture and followed by pressing into transparent slices for analysis.

\section{Purity test with HPLC}

The purity test of isolated piperine was carried out using HPLC Hitachi L-2420 with isocratic elution, UV detector at $340 \mathrm{~nm}$, a mobile phase of methanol: water (75:25), stationary phase Luna 85 M C18 $100 \AA$ AC Column 250 x 4.6 $\mathrm{mm}$ Phenomenex, flow rate $1 \mathrm{~mL} / \mathrm{min}$, column temperature of $25^{\circ} \mathrm{C}$, and sample injection of $20 \mu \mathrm{L}$ (Chithra et al., 2014; Hamrapurkar et al., 2011). Samples were dissolved in methanol.

\section{NMR Test}

${ }^{1} \mathrm{H}$ and ${ }^{13} \mathrm{C}$ NMR spectra were obtained from a test using NMR JNM-ECZ500R spectrophotometer, $500 \mathrm{MHz}$ Super Conductive Magnet. Samples were dissolved in deuterated methanol (CD30D) containing trace amounts of tetramethylsilane and then inserted into the NMR spectrometer. The spectra of isolated piperine were compared to those of the reference substance. 


\section{RESULT AND DISCUSSION}

Thin Layer Chromatographic Profiles of Extract Obtained by Extractions

The thin layer chromatographic profile of extract obtained by extraction with n-hexane and that with ethanol (Figure 1). The TLC profile (Figure 1) shows that the n-hexane extract contained impurities only in the upper part of the piperine spot, while the ethanolic extract might contain both non-polar substances and more polar substances in the lower part of the piperine spot. This is due to the nature of the n-hexane solvent which is non-polar and suitable to attract non-polar compounds. Meanwhile, ethanol solvents contain polar and non-polar groups, suitable for extraction of polar and non-polar compounds, especially compounds that have hydroxyl groups (Do et al., 2014; Escorsim et al., 2018). The ethanolic extract contained more piperine than that of the n-hexane with the same duration of extraction. Based on the TLC profiles (Figure 1) of the ethanolic and nhexane extract, the ethanolic extract produced the same spot with more concentration in comparison to the n-hexane extract. This shows that the ethanolic extract contained more piperine than the $\mathrm{n}$-hexane extract because the penetration power of ethanol was stronger than the n-hexane (Baümler et al., 2016). The amount of piperine in the nhexane extract could increase and achieve the same level as those of the ethanolic extract if the duration of extraction is increased three times longer than the latter (Hamrapurkar et al., 2011; Khan et al., 2017; Subramanian et al., 2016). On the other side, the elimination of polar substances in the ethanolic extract may be performed by fractionation using $n$ hexane, but it would take more extraction steps. The elimination of polar substances in the ethanolic extract can also be achieved by evaporation of solvent followed by the addition of potassium hydroxide alcoholic solution. The resinous material will be precipitated. This last-mentioned procedure can only be performed on a laboratory scale due to the inconvenient use of potassium hydroxide on a large scale, which will cause environmental pollution. Based on the above-mentioned conditions, the n-hexane extraction was the best method for piperine extraction. In this research, the extraction with Soxhlet apparatus was performed on $300 \mathrm{~g}$ white pepper powder, and after the removal resinous matter with cyclohexane yielded $2.49 \mathrm{~g}$ of isolated piperine or $0.83 \%$ yield.
The organoleptic properties of the isolated piperine were crystalline powder, yellowish-white, odorless, and pungent taste.

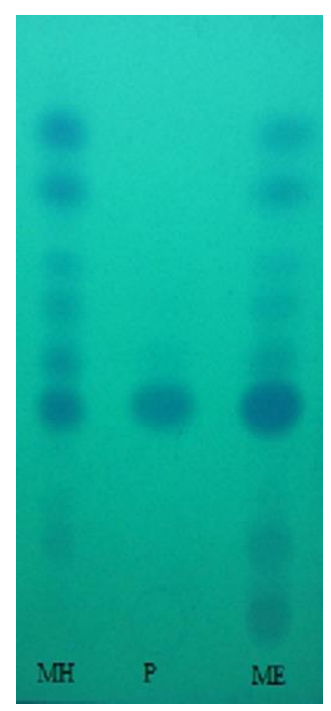

Figure 1. TLC profile of white pepper extracts. Stationary phase: Silica gel F254, Mobile phase: nHexane:Ethyl acetate (7:3), Detection: $\mathrm{UV}_{254}$. MH: $n$-Hexane extract, ME: Ethanolic extract, P: Piperine reference substance.

\section{Identification Isolated Crystal}

The isolated crystal from $P$. nigrum and piperine reference substance had melting points of $123-124^{\circ} \mathrm{C}$ and $123-123.8^{\circ} \mathrm{C}$, respectively. It can be concluded that the isolated crystal had similar properties to the piperine reference substance obtained from E.Merck.

\section{Bidimensional Thin-Layer Chromatography}

The bidimensional TLC aimed to ensure the purity of the isolated piperine using the chromatogram results. The test was expected to produce one spot on the first elution and the second elution using a different mobile phase system (Figure 2).

The results of the isolated piperine with bidimensional TLC (Figure 2) shows that the first elution produced one spot with an Rf value of 0.42 , while the second elution produced one spot with an Rf value of 0.38. Based on the results of the purity test using bidimensional TLC, it can be concluded that the isolated piperine obtained was pure. 


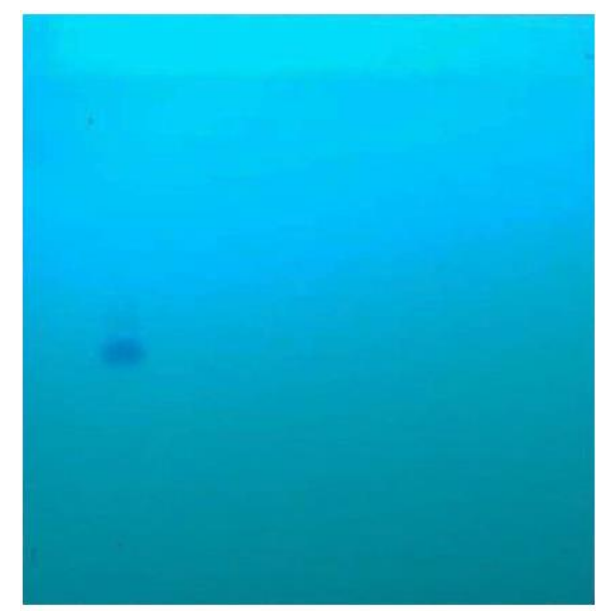

(a)

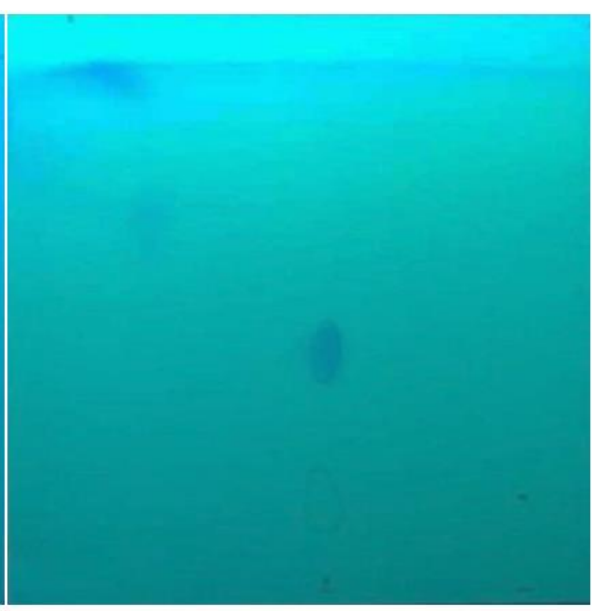

(b)

Figure 2. The results of bidimensional TLC under UV $254 \mathrm{~nm}$ (a) eluted with n-hexane-ethyl acetate (9:5) (b) eluted with cyclohexane-chloroform (1:4)

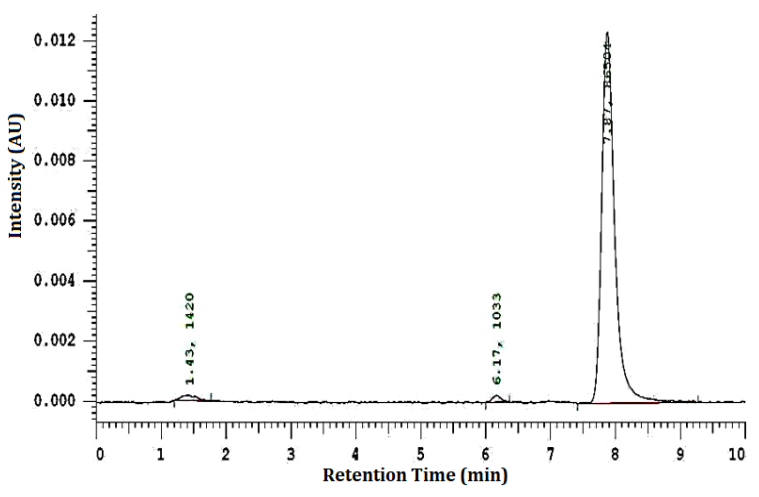

Figure 3. Chromatogram of isolated piperine at $340 \mathrm{~nm}$

\section{Purity test using HPLC}

The isolated piperine from hexane extract was analyzed and identified by HPLC using a previously validated method $(\mathrm{y}=148.11 \mathrm{x}+8208.6$, $r \geq 0.9999$ ). Pure piperine was used as a reference for identification using HPLC. The obtained results (Figure 3) showed one peak corresponding to the isolated piperine in comparison to the reference substance (Figure 4), which appeared at the same retention time (7.88min), and the percent area of isolated piperine and piperine reference substance were $97.24 \%$ and 98.76\%, respectively. Meanwhile, the peak that was apparent at 6.10 minutes was possibly piperic acid compounds, which were more polar than piperine compounds (Zarai et al., 2013). According to the quantification results using the validated analytical method, the isolated sample contained $94.57 \pm 0.82 \%$ piperine.

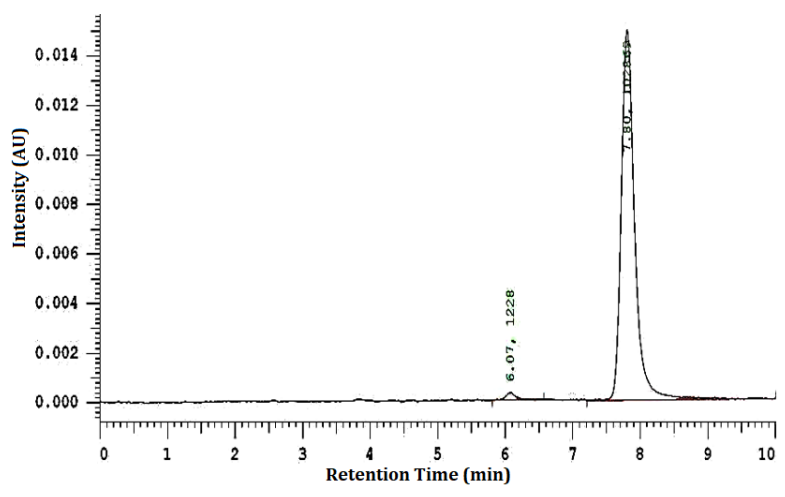

Figure 4. Chromatogram of piperine reference sub stance at $340 \mathrm{~nm}$

\section{FTIR analysis}

FTIR analysis was performed to prove that the isolated piperine and the piperine reference substance have similarities in their spectra to confirm the functional groups and determine the molecular structure of the isolated piperine. The peak positions and functional groups in the piperine molecule (Figure 5) (Table I). The peak positions and interatomic bonds of the piperine structure are as follows: the peaks at 2800-3000, 1635, 1495-1589, 1030-1257, and 1134 and may indicate the presence of $\mathrm{CH}$ functional groups, $\mathrm{C}-\mathrm{H} 2, \mathrm{O}=\mathrm{C}-\mathrm{N}, \mathrm{C}=\mathrm{C},=\mathrm{C}-\mathrm{O}-\mathrm{C}$, and C-O-C, respectively (Shingate et al., 2013; Silverstein and Bassler, 1962). The similarity proved that the isolated piperine has a similar structure to the reference substance. 


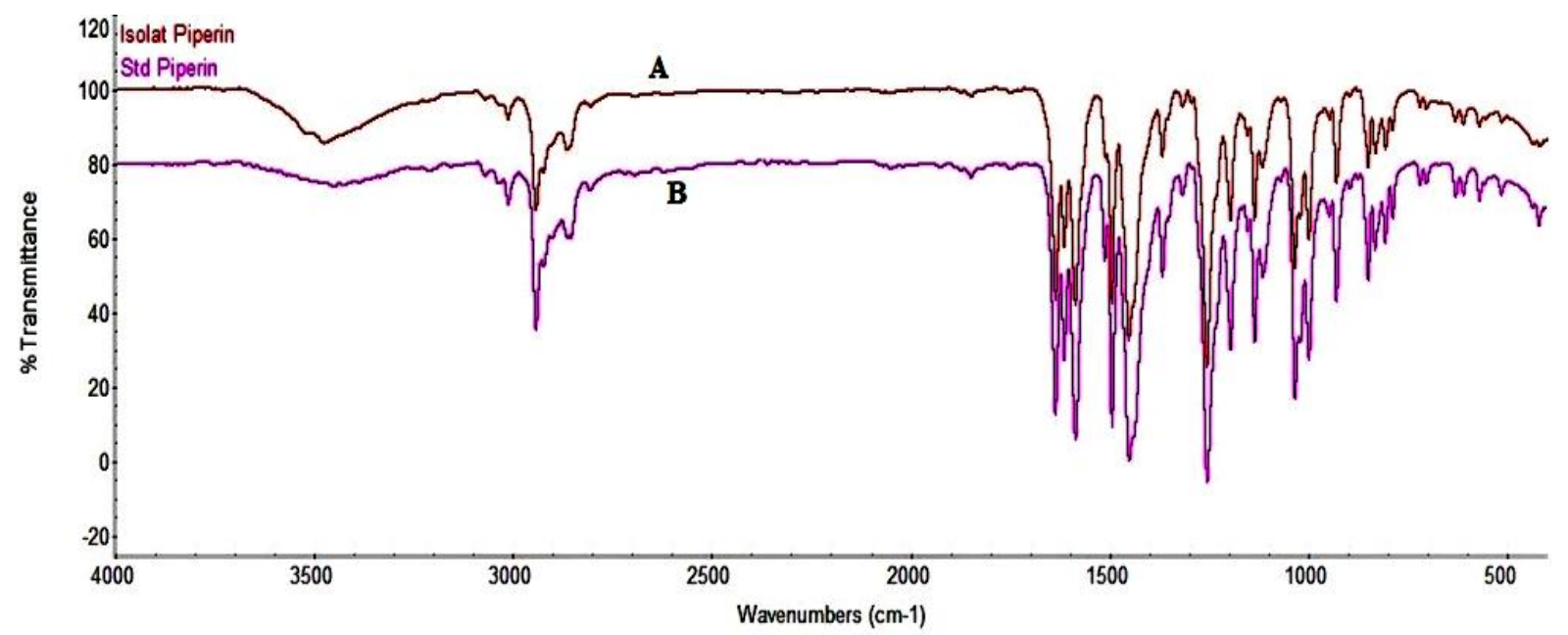

Figure 5. FTIR spectra of isolated piperine (A) and piperine reference substance (B)

Table I. The comparison of IR spectra of isolated piperine and piperine reference substance

\begin{tabular}{lcc}
\hline Type of phenomenon & $\begin{array}{c}\text { piperine reference } \\
\text { substance IR values }\end{array}$ & $\begin{array}{c}\text { Isolated piperine } \\
\text { IR values }\end{array}$ \\
\hline Aromatic C-H stretching & 3008.95 & 3008.95 \\
Symmetric and asymmetric stretching of C=C diene & 1635.64 & 1635.64 \\
Aromatic stretching of C=C (benzene ring) & 1589.34 & 1581.63 \\
& 1495 & 1495 \\
Stretching of -CO-N & 1635.64 & 1635.64 \\
Asymmetric and symmetric CH2 stretching, aliphatic C-H & 2939.52 & 2939.52 \\
stretching & 2854.65 & 2862.36 \\
CH2 bending & 1442.75 & 1442.75 \\
Asymmetrical stretdhing =C-O-C & 1257.59 & 1257.59 \\
& 1195.87 & 1195.87 \\
Symmetrical stretching =C-O-C & 1033.85 & 1033.85 \\
C-O stretching in-plane bending of phenyl C-H & 1134.14 & 1134.14 \\
C-H bending of trans -CH=CH- & 995.27 & 995.27 \\
Out-of-plane C-H bending 1,2,4- trisubstituted phenyl (two & 848.68 & 848.68 \\
adjacent hydrogen atoms) & 802.39 & 802.39 \\
\hline
\end{tabular}

\section{NMR analysis}

NMR analysis was carried out to determine the chemical structure and the purity of the isolated compound. Structural elucidation results were obtained based on NMR analysis, while the purity of the piperine compound (Figure 6) was confirmed by ${ }^{1} \mathrm{H}$ and ${ }^{13} \mathrm{C}-\mathrm{NMR}$ spectral data.

The results of the ${ }^{13} \mathrm{C}$-NMR spectrum of the isolated piperine (Figure7) showed that there were $17 \mathrm{C}$ atoms with the following signals: $\delta 25.71(\mathrm{C}-$ 13), $\delta 27.05$ (C-14), $\delta 28.04$ (C-14), $\delta 44.70$ (C-15), $\delta 48.28$ (C-15), $\delta 102.87$ (C-12), $\delta 106.83$ (C-7), $\delta$
109.83 (C-9), $\delta 120.79$ (C-2), $\delta 126.56$ (C-8), $\delta$ 140.319 (C-5), $\delta 132.57$ (C-6), $\delta 124.04$ ( C-4), $\delta$ 144.74 (C-3), $\delta 149.92$ (C-10), $\delta 149.95$ (C-11), and $\delta 167.89(\mathrm{C}-1)$ (Table II). The signal of methanol solvent was observed around $48.64-49.67 \mathrm{ppm}$. All ${ }^{13} \mathrm{C}$-NMR values were similar to the previous studies (Alves et al., 2019). The use of different solvents in the NMR analysis in the previous studies (Alves et al., 2019) gave a slight shift in the ${ }^{13} \mathrm{C}-\mathrm{NMR}$ signals produced. Signal peaks in the range of $0-50$ ppm represented carbon-carbon single bonds, peaks in the range of $101 \mathrm{ppm}$ represented carbon-oxygen atoms in the molecule. 


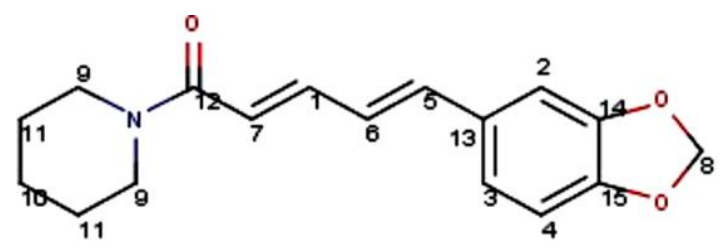

Figure 6. The molecular structure of isolated piperine

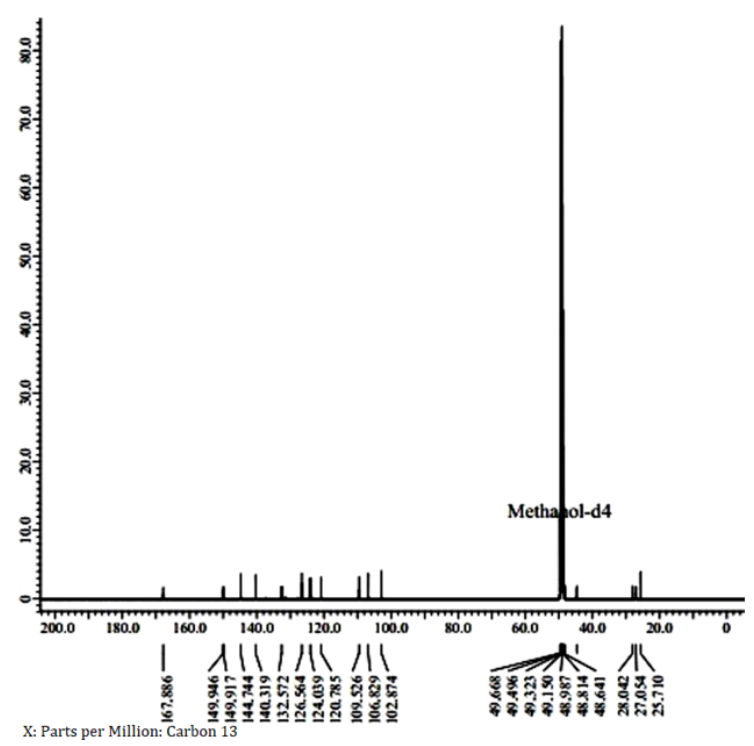

Figure $7 .{ }^{13} \mathrm{C}-\mathrm{NMR}$ spectrum of isolated piperine

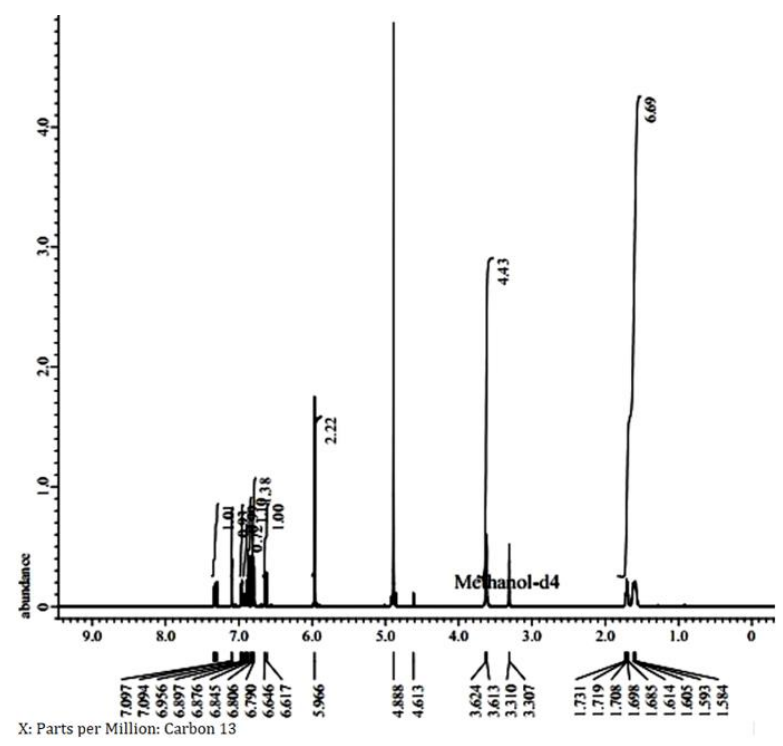

Figure $8 .{ }^{1} \mathrm{H}-\mathrm{NMR}$ spectrum of isolated piperine

Table II. ${ }^{13} \mathrm{C}-\mathrm{NMR}$ and ${ }^{1} \mathrm{H}$-NMR spectra of the isolated piperine

\begin{tabular}{lll}
\hline No Atom & 13C-NMR $\boldsymbol{\delta}$ (ppm) & 1H-NMR $\boldsymbol{\delta}$ (ppm) \\
\hline $\mathbf{1 3}$ & 25.710 & $1.584-1.614$, multiplet, $2 \mathrm{H}$ \\
$\mathbf{1 4}$ & 27.054 & $1.685-1.731$, multiplet, $2 \mathrm{H}$ \\
$\mathbf{1 4}$ & 28.042 & $1.685-1.731$, multiplet, $2 \mathrm{H}$ \\
$\mathbf{1 5}$ & 44.696 & $3.613-3.635$, multiplet, $2 \mathrm{H}$ \\
$\mathbf{1 5}$ & 48.277 & $3.613-3.635$, multiplet, $2 \mathrm{H}$ \\
$\mathbf{1 2}$ & 102.874 & 5.966, singlet, $2 \mathrm{H}$ \\
$\mathbf{7}$ & 106.829 & $7.094-7.097$, multiplet, $1 \mathrm{H}$ \\
$\mathbf{9}$ & 109.526 & 6.845, doublet, $1 \mathrm{H}$ \\
$\mathbf{2}$ & 120.785 & 6.617, doublet, $1 \mathrm{H}$ \\
$\mathbf{8}$ & 126.564 & 6.876, doublet, $1 \mathrm{H}$ \\
$\mathbf{5}$ & 140.319 & 6.806, multiplet, $1 \mathrm{H}$ \\
$\mathbf{6}$ & 132.572 & - \\
$\mathbf{4}$ & 124.039 & 6.790, multiplet, $1 \mathrm{H}$ \\
$\mathbf{3}$ & 144.744 & $7.296-7.347$, doublet of doublet, $1 \mathrm{H}$ \\
$\mathbf{1 0}$ & 149.917 & - \\
$\mathbf{1 1}$ & 149.946 & - \\
$\mathbf{1}$ & 167.886 & - \\
\hline
\end{tabular}


Peaks in the range 100-150 and 167.89 corresponded to carbon-carbon double bonds and carbon-oxygen double bonds, respectively

The ${ }^{1} \mathrm{H}-\mathrm{NMR}$ spectrum of the isolated piperine (Figure8) showed 19 protons with the following signals: $\delta 1.599(2 \mathrm{H}, \mathrm{m}, \mathrm{H}-13), \delta 1.708$ (2H, m, H-14), $\delta 3.624$ (2H, m, H-15), $\delta 5.966$ (2H, $\mathrm{s}, \mathrm{H}-12), \delta 7.0956$ (1H, m, H-7), $\delta 6.845$ (1H, d, H-9), $\delta 6.617(\mathrm{IH}, \mathrm{d}, \mathrm{H}-2), \delta 6.876(1 \mathrm{H}, \mathrm{d}, \mathrm{H}-8), \delta 6.806$ $(1 \mathrm{H}, \mathrm{d}, \mathrm{H}-5), \delta 6.790(1 \mathrm{H}, \mathrm{m}, \mathrm{H}-4)$, and $\delta 7.3215(1 \mathrm{H}$, ddd, H-3). The methanol solvent signal was observed around $3.31 \mathrm{ppm}$ and $4.88 \mathrm{ppm}$. The ${ }^{1} \mathrm{H}-$ NMR piperine signal was similar to the previously reported NMR of the piperine compound (Alves et al., 2019).

\section{CONCLUSION}

Cyclohexane has been successfully used to remove resinous matter from the $n$-hexane extract of white pepper in the production of isolated piperine with $94.57 \pm 0.82 \%$ of purity. The melting point, ${ }^{1} \mathrm{H}-\mathrm{NMR}$, and ${ }^{13} \mathrm{C}-\mathrm{NMR}$ spectra of the isolated piperine were similar to those of piperine reference substances in the literature. The simple isolation method and the technical grade solvent used in this study open up the possibility to apply the method for industrial scale production. Moreover, the isolated piperine can potentially be used as an active pharmaceutical ingredient (API) in pharmaceutical dosage forms.

\section{ACKNOWLEDGMENT}

The authors would like to thank the Ministry of Research, Technology, and Higher Education of the Republic of Indonesia for providing financial support during this research via the MasterDoctoral Program for Excellent Graduate Student (PMDSU) scheme.

\section{REFERENCES}

Alves, F. S., Rodrigues Do Rego, J. de A., Da Costa, M. L., Lobato Da Silva, L. F., Da Costa, R. A., Cruz, J. N., \& Brasil, D. D. S. B. (2019). Spectroscopic methods and in silico analyses using density functional theory to characterize and identify piperine alkaloid crystals isolated from pepper (Piper Nigrum L.). Journal of Biomolecular Structure and Dynamics, 1-8. https://doi.org/10.1080/07391102.2019. 1639547

Baümler, E. R., Carrín, M. E., \& Carelli, A. A. (2016). Extraction of sunflower oil using ethanol as solvent. Journal of Food Engineering,
178 ,

190-197.

https://doi.org/10.1016/j.jfoodeng.2016. 01.020

Chaudhri, V. K. (2017). Isolation and Evaluation of Piperine from Black Pepper and White Pepper. World Journal of Pharmacy and Pharmaceutical Sciences, 1424-1430. https://doi.org/10.20959/wjpps201789752

Chithra, S., Jasim, B., Sachidanandan, P., Jyothis, M., \& Radhakrishnan, E. K. (2014). Piperine production by endophytic fungus Colletotrichum gloeosporioides isolated from Piper nigrum. Phytomedicine, 21(4), 534-540.

https://doi.org/10.1016/j.phymed.2013. 10.020

Do, Q. D., Angkawijaya, A. E., Tran-Nguyen, P. L., Huynh, L. H., Soetaredjo, F. E., Ismadji, S., \& Ju, Y.-H. (2014). Effect of extraction solvent on total phenol content, total flavonoid content, and antioxidant activity of Limnophila aromatica. Journal of Food and Drug Analysis, 22(3), 296-302. https://doi.org/10.1016/j.jfda.2013.11.0 01

Ee, G. C. L., Lim, C. M., Rahmani, M., Shaari, K., \& Bong, C. F. J. (2010). Pellitorine, a potential anti-cancer lead compound against HL6 and MCT-7 cell lines and microbial transformation of piperine from Piper Nigrum. Molecules (Basel, Switzerland), 15(4), 2398-2404. https://doi.org/10.3390/molecules15042 398

Escorsim, A. M., da Rocha, G., Vargas, J. V. C., Mariano, A. B., Ramos, L. P., Corazza, M. L., \& Cordeiro, C. S. (2018). Extraction of Acutodesmus obliquus lipids using a mixture of ethanol and hexane as solvent. Biomass and Bioenergy, 108, 470-478. https://doi.org/10.1016/j.biombioe.2017 .10 .035

Hamrapurkar, P. D., Jadhav, K., \& Zine, S. (2011). Quantitative estimation of piperine in Piper nigrum and Piper longum using high performance thin layer chromatography. Journal of Applied Pharmaceutical Science, 1, 117-120.

Han, Y., Chin Tan, T. M., \& Lim, L.-Y. (2008). In vitro and in vivo evaluation of the effects of piperine on P-gp function and expression. Toxicology and Applied Pharmacology, 230(3), 283-289. 
https://doi.org/10.1016/j.taap.2008.02.0 26

Ikan, R. (2013). Natural Products: A Laboratory Guide. Elsevier.

Khan, Z., Moni, F., Sharmin, S., Al-Mansur, M., Gafur, A., Rahman, O., \& Afroz, F. (2017). Isolation of Bulk Amount of Piperine as Active Pharmaceutical Ingredient (API) from Black Pepper and White Pepper ( Piper nigrum L.). Pharmacology \& Pharmacy, 08, 253-262. https://doi.org/10.4236/pp.2017.87018

Koul, I. B., \& Kapil, A. (1993). Evaluation of the liver protective potential of piperine, an active principle of black and long peppers. Planta Medica, 59(5), 413-417. https://doi.org/10.1055/s-2006-959721

Li, L., Liu, H., Shi, W., Liu, H., Yang, J., Xu, D., Huang, H., \& Wu, L. (2017). Insights into the Action Mechanisms of Traditional Chinese Medicine in Osteoarthritis. Evidence-Based Complementary and Alternative Medicine. https://doi.org/10.1155/2017/5190986

Li, S., Wang, C., Wang, M., Li, W., Matsumoto, K., \& Tang, Y. (2007). Antidepressant like effects of piperine in chronic mild stress treated mice and its possible mechanisms. Life Sciences, $\quad$ 80(15), 1373-1381. https://doi.org/10.1016/j.lfs.2006.12.027

Mujumdar, A. M., Dhuley, J. N., Deshmukh, V. K., Raman, P. H., \& Naik, S. R. (1990). Antiinflammatory activity of piperine. Japanese Journal of Medical Science \& Biology, 43(3), 95-100.

https://doi.org/10.7883/yoken1952.43.9 5

Rahman, A., Chakma, J. S., Islam, S., \& Uddin, N. (2011). Evaluation of antioxidant, antibacterial, antifungal and cytotoxic effects of Clausena suffruticosa ethanolic root extract. Journal of Applied Pharmaceutical Science, 01(05), 90-95.

Saha, K., Seal, H., \& Noor, M. (2014). Isolation and characterization of piperine from the fruits of black pepper (Piper nigrum). Journal of the Bangladesh Agricultural University, 11(1), 11-16. https://doi.org/10.3329/jbau.v11i1.1819 7
Shingate, P. N., Dongre, P. P., \& Kannur, D. M. (2013). New Method Development For Extraction and Isolation of Piperine From Black Pepper. International Journal of Pharmaceutical Sciences and Research, 4(8), 3165-3170.

Silverstein, R. M., \& Bassler, G. C. (1962). Spectrometric identification of organic compounds. Journal of Chemical Education, 39(11), 546.

Srinivasan, K. (2007). Black pepper and its pungent principle-piperine: A review of diverse physiological effects. Critical Reviews in Food Science and Nutrition, 47(8), 735748.

https://doi.org/10.1080/104083906010 62054

Subramanian, R., Subbramaniyan, P., Noorul Ameen, J., \& Raj, V. (2016). Double bypasses soxhlet apparatus for extraction of piperine from Piper nigrum. Arabian Journal of Chemistry, 9, S537-S540. https://doi.org/10.1016/j.arabjc.2011.06. 022

Umar, S., Golam Sarwar, A. H. M., Umar, K., Ahmad, N., Sajad, M., Ahmad, S., Katiyar, C. K., \& Khan, H. A. (2013). Piperine ameliorates oxidative stress, inflammation and histological outcome in collagen induced arthritis. Cellular Immunology, 284(1-2), 51-59.

https://doi.org/10.1016/j.cellimm.2013.0 7.004

Ying, X., Chen, X., Cheng, S., Shen, Y., Peng, L., \& Xu, H. zi. (2013). Piperine inhibits IL- $\beta$ induced expression of inflammatory mediators in human osteoarthritis chondrocyte. International Immunopharmacology, 17(2), 293-299. https://doi.org/10.1016/j.intimp.2013.06 .025

Zarai, Z., Boujelbene, E., Ben Salem, N., Gargouri, Y., \& Sayari, A. (2013). Antioxidant and antimicrobial activities of various solvent extracts, piperine and piperic acid from Piper nigrum. LWT - Food Science and Technology, 50(2), 634-641. https://doi.org/10.1016/j.lwt.2012.07.03 6 